\title{
Selective sparing of face learning in a global amnesic patient
}

\author{
G A Carlesimo, L Fadda, P Turriziani, F Tomaiuolo, C Caltagirone
}

\begin{abstract}
Objective-To test the hypothesis that visual memory for faces can be dissociated from visual memory for topographical material.

Method-A patient who developed a global amnesic syndrome after acute carbon monoxide poisoning is described. A neuroradiological examination documented severe bilateral atrophy of the hippocampi.

Results-Despite a severe anterograde memory disorder involving verbal information, abstract figures, concrete objects, topographical scenes, and spatial information, the patient was still able to learn previously unknown human faces at a normal (and, in some cases, at a higher) rate.

Conclusions-Together with previous neuropsychological evidence documenting selective sparing of topographical learning in otherwise amnesic patients, this case is indicative of the fact that the neural circuits involved in face recognition are distinct from those involved in the recognition of other visuoperceptual material (for example, topographical scenes).

(F Neurol Neurosurg Psychiatry 2001;71:340-346)
\end{abstract}

Keywords: face learning; amnesia

Convergent lines of evidence indicate that the recognition of faces and topographical scenes is subserved in the human brain by the operation of anatomically proximal but reciprocally distinct cortical areas situated in the ventrome-

IRCCS S Lucia,

V. Ardeatina 306, 00179

Roma, Italy

G A Carlesimo

L Fadda

P Turriziani

F Tomaiuolo

C Caltagirone

Clinica Neurologica, Università di Roma

Tor Vergata, Italy

G A Carlesimo

L Fadda

C Caltagirone

Correspondence to: Dr G A Carlesimo

memolab@hsantalucia.it

Received 3 October 2000 and in revised form

5 April 2001

Accepted 23 April 2001 landscapes) and is generally known as landmark agnosia. ${ }^{4-7}$ The second results from deficient processing of the spatial characteristics of the environment (spatial agnosia) or from memory loss of spatial relations in the environment. It is characterised by the fact that relevant landmarks, although normally recognised, have lost their directional value (topographical amnesia). ${ }^{8}$

The preferential locus of a cortical lesion in both prosopagnosia ${ }^{9}$ and topographical disorientation $^{10}$ is the inferomedial surface of the occipitotemporal lobes, most often as a result of an ischaemia in the territory supplied by the right posterior cerebral artery. Although prosopagnosia and topographical disorientation generally occur together in the same patient - so that the choice of reporting the patient as prosopagnosic ${ }^{11}$ or as disoriented ${ }^{12}$ is often just a matter of preference-the previous claim of distinct cortical areas underlying the recognition of faces or places is supported by evidence that the association between the two syndromes is not obligatory. Occasionally, prosopagnosia may occur without any sign of topographical disorientation. ${ }^{12-15}$ It may also persist after resolution of the topographical disorientation. ${ }^{16}$ Analogously, patients have been reported whose inability to recognise previously well known places is not accompanied by any face recognition difficulty. ${ }^{14}$

The anatomical contiguity and, at the same time, the reciprocal segregation of cortical areas mediating the recognition of faces or the recognition of topographical landmarks, has been confirmed by the results of functional neuroimaging investigation. Aguirre et $a l^{17}$ submitted healthy subjects to functional MRI while they were attempting to learn a set of unknown buildings or a set of unfamiliar faces. By reciprocally subtracting the respective areas of cortical activation, these authors were able to demonstrate that distinct regions in the ventromesial cortex of the right temporal and occipital lobes are specifically activated by the face or the building learning task. In particular, a region encroaching on the right lingual sulcus showed a significantly greater functional MRI signal during the presentation of buildings than faces. Conversely, a region in the right fusiform gyrus, inferior and lateral to the building specialised area, was significantly more active during the face than the building learning task.

Recent evidence suggests that the neuropsychological dissociation between impaired memory for faces and preserved memory for topographical material may extend (and in some cases be limited) to the anterograde domain. Cipolotti et $a l^{18}{ }^{19}$ reported on two 

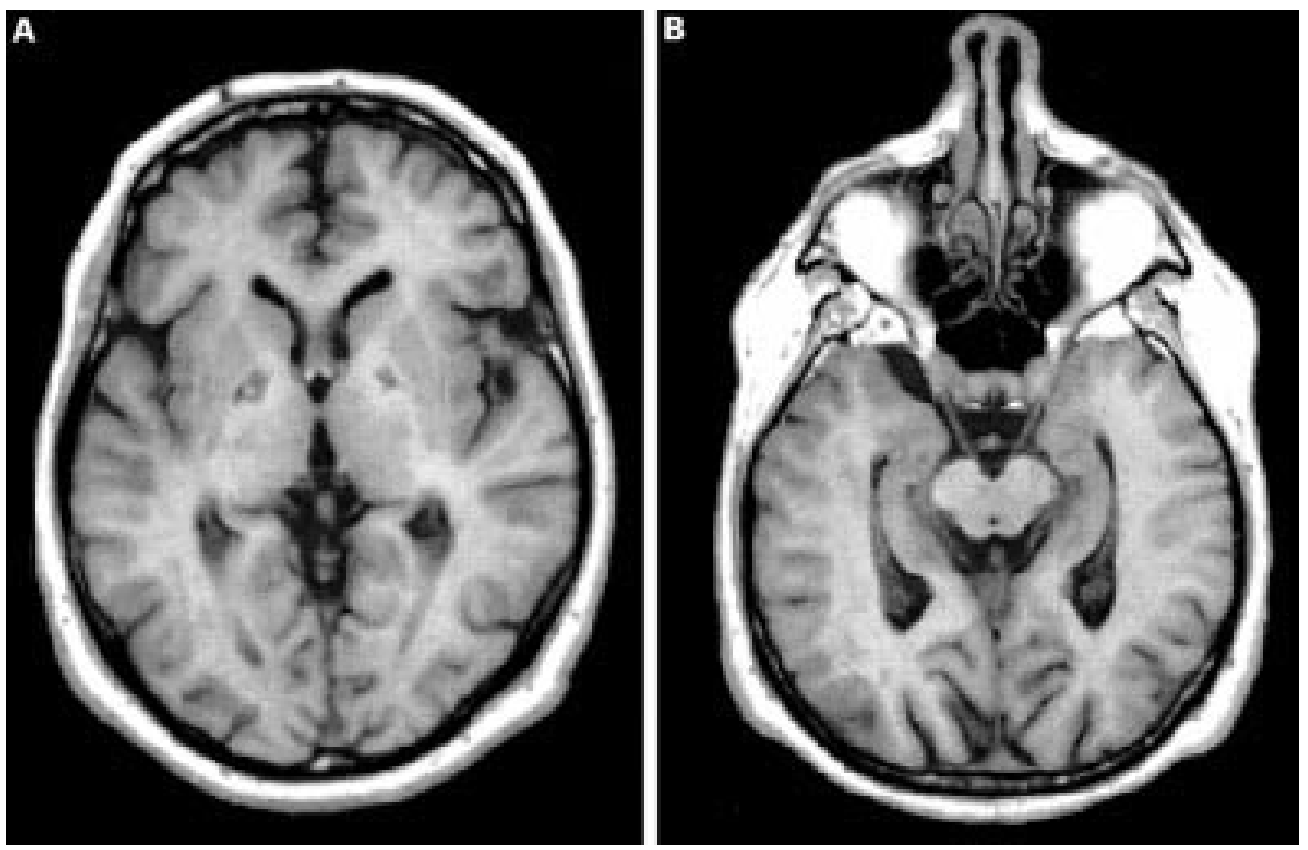

Figure 1 Axial slices of patient's brain MRI documenting focal lesions affecting $(A)$ the globus pallidi bilaterally and (B) the volumetric reduction of the hippocampi.

patients with a severe deficit in learning new faces who were perfectly able to learn new topographical material such as buildings and routes. The first patient, a 61 year old woman, was diagnosed as having Pick's disease. Her general intelligence as well as her ability to learn verbal material and new faces progressively deteriorated during 5 years of clinical and neuropsychological observation. However, during this time her ability to recognise and orient herself in previously known places and to learn the visual aspect of previously unknown topographical scenes as well as new routes remained intact. The second patient, a 29 year old man, was deaf from birth and affected by autism and Tourette's syndrome. Despite this, his intelligence was normal. Although he was very poor in learning new faces, his ability to learn new topographical material (the visual aspect of both landmarks and routes) was excellent. Another patient, potentially relevant to this issue, was recently reported by Tippett et al. ${ }^{20}$ The patient, a 35 year old man, had had a head trauma 10 years before and had undergone right temporal lobectomy 5 years before neuropsychological testing for relief from intractable epileptic seizures. He performed within the normal range on all tests of a neuropsychological battery administered to investigate his episodic memory for various materials (words, abstract figures, concrete objects); however, he scored poorly on tests exploring the learning of new faces. As this patient did not have any apparent difficulty in remembering the faces of people he had known before the trauma, his case was designated isolated anterograde prosopamnesia (as opposed to the classic syndrome of prosopagnosia, involving both anterograde and retrograde memory deficits for faces). Unfortunately, as the authors did not report a detailed investigation of their patient's ability to learn new topographical material, we cannot be sure that in the visuoperceptual domain his anterograde memory deficit was really limited to physiognomic material.

We describe a patient whose neuropsychological profile is complementary to that of the patients reported by Cipolotti et al, ${ }^{18}$ Maguire and Cipolotti, ${ }^{19}$ and Tippett et al. ${ }^{20}$ This patient developed a global amnesic syndrome as the result of acute carbon monoxide poisoning. In the context of a severe anterograde memory impairment involving verbal, spatial, and visuoperceptual material (including topographical scenes), his ability to learn new faces remained normal and in some cases was superior to that of normal controls.

\section{Case report}

The patient, a 47 year old fireman, suffered acute carbon monoxide poisoning in October 1998 while involved in putting out a fire. An initial loss of consciousness resolved 2 hours after hospital admission. However, the patient remained confused and agitated for 2 days and was released from the intensive care unit on the 8th day after admission to hospital.

We first saw this patient in February 1999. At that time, he was fully alert and cooperative. A temporal disorientation, evident at the first examination, rapidly resolved. His neurological examination was unremarkable with the exception of a mild extrapyramidal dysarthria. His main complaint was a severe impairment in retaining day to day events and information. His wife reported that he asked the same questions over and over, had great difficulty in learning new routes, and needed to take a list even to buy a few items at the market.

Remote memories regarding his preaccident life, basic cultural knowledge, public events, and familiar people were apparently preserved. However, sometimes he had difficulty in orienting himself in well known places in 
Table 1 Patient's performances on the tests of the general neuropsychological examination

\begin{tabular}{|c|c|c|c|}
\hline & Patient score & $\begin{array}{l}\text { Maximum } \\
\text { score possible }\end{array}$ & Percentile score \\
\hline \multicolumn{4}{|l|}{ Wechsler adult intelligence scale ${ }^{22}$ : } \\
\hline Verbal IQ & 107 & & \\
\hline Performance IQ & 110 & & \\
\hline Full Scale IQ & 109 & & \\
\hline \multicolumn{4}{|l|}{ Wechsler memory scale quotient ${ }^{23}$ : } \\
\hline MQ & 77 & & \\
\hline Raven's coloured progressive matrices ${ }^{24}$ & 27.3 & 36 & $>25$ \\
\hline Phrase construction ${ }^{25}$ & 23 & 25 & $>50$ \\
\hline \multicolumn{4}{|l|}{ Copying drawings $^{25}$} \\
\hline Free copy & 7.3 & 12 & $>5$ \\
\hline With landmarks & 69 & 70 & $>50$ \\
\hline Wisconsin card sorting test ${ }^{26}$ : & & & Range of normal controls \\
\hline Criteria achieved & 6 & 6 & $2-6$ \\
\hline Perseverative errors & 1 & 0 & $0-6$ \\
\hline Total errors & 6 & 0 & $0-24$ \\
\hline
\end{tabular}

References are those from which normative data and percentile scores of single tests were derived. For the Wisconsin card sorting test, the range of performance scores achieved by 10 age matched normal controls is reported (normative data collected from an Italian population are not available)

Rome, even though he had driven a fire engine there for many years. His wife also noted a change in his personality. Before the accident he was described as very active and often engaged in activities outside work. After the accident he was apathetic, lacked initiative, and preferred to spend most of his time at home.

Behavioural observation indicated that the patient had retained the ability to learn new faces. After his first encounter with a member of the laboratory staff, the patient was able to recognise him outside the laboratory context. However, when specifically asked he denied recognising newly encountered faces better than other new information (for example, routes or proper names). Actually, it seemed that the patient was unable to associate new faces with the temporospatial context in which the person was first encountered or with the person's proper name. This resulted in a sense of familiarity for the face that was nevertheless spoiled from other information relevant for the person's identification.

The neuroradiological and neuropsychological examinations reported below were conducted between January and November 1999.
NEURORADIOLOGICAL INVESTIGATION

Brain MRI was performed in April 1999 (fig 1 ). As is typically seen in patients who have undergone carbon monoxide poisoning, ${ }^{21}$ the brain showed lesions affecting the globus pallidus bilaterally (fig $1 \mathrm{~A}$ ). No other focal lesions were detected. However, there was an evident reduction of the hippocampal volume bilaterally (fig $1 \mathrm{~B}$ ).

GENERAL NEUROPSYCHOLOGICAL EXAMINATION The patient's performance scores on neuropsychological and psychometric tests are reported in table 1 . His scores were essentially normal on tests assessing general intelligence (WAIS, Raven's coloured progressive matrices), language (sentence construction), visuoconstructive abilities (copying drawings with and without pre-designed landmarks), and executive functions (Wisconsin card sorting test). However, his performance was very poor on the Wechsler memory scale. In fact, his memory quotient was more than 30 points below his intelligence quotient.

\section{MEMORY}

The patient's performance scores on a battery of tests assessing memory functioning are reported in table 2 . He had normal short term memory as shown by performance scores within normal limits on tests of verbal and spatial spans and on a test (immediate visual memory) evaluating immediate recognition of non-verbalisable drawings among four visually similar alternatives.

However, his episodic long term memory was severely impaired. His scores on the 15 minute delayed free recall of a 15 word list were pathological. In the five immediate recall trials of the same list, the patient's score was above the fifth percentile of the normal population. However, a qualitative analysis of his performance showed that the patient relied almost exclusively on his intact short term memory for the immediate recall. In fact, $62 \%$ of his overall recall was represented by words located in the

Table 2 Patient's performances on the memory tests

\begin{tabular}{|c|c|c|c|}
\hline & Patient score & $\begin{array}{l}\text { Maximum score } \\
\text { possible }\end{array}$ & Percentile score \\
\hline \multicolumn{4}{|l|}{ Verbal short term memory: } \\
\hline Digit span forward ${ }^{28}$ & 5.75 & 9 & $>50$ \\
\hline \multicolumn{4}{|l|}{ Visuospatial short term memory: } \\
\hline Corsi block test forward ${ }^{28}$ & 3.75 & 9 & $<10$ \\
\hline Immediate visual memory ${ }^{24}$ & 13.8 & 22 & $>50$ \\
\hline \multicolumn{4}{|l|}{ Verbal long term memory: } \\
\hline \multicolumn{4}{|l|}{ Rey's 15 words learning task ${ }^{24}$} \\
\hline Immediate recall & 31 & 75 & $<10$ \\
\hline 15 minute delayed recall & 0 & 15 & $<5$ \\
\hline Short story recall ${ }^{29}$ & 0 & 16 & $<5$ \\
\hline \multicolumn{4}{|l|}{ Visuospatial long term memory: } \\
\hline \multicolumn{4}{|l|}{ Rey's figure A } \\
\hline Immediate reproduction & 0 & 36 & $<5$ \\
\hline 15 minute delayed reproduction & 0 & 36 & $<5$ \\
\hline Supraspan spatial learning ${ }^{29}$ & 1.16 & 30.78 & $<5$ \\
\hline \multicolumn{4}{|l|}{ Camden memory battery ${ }^{27}$ : } \\
\hline Short recognition memory test for faces & 22 & 25 & 25 \\
\hline Topographical recognition memory test & 20 & 30 & 10 \\
\hline Pictorial recognition memory test & 24 & 30 & $<1 \%$ \\
\hline Short recognition memory test for words & 14 & 25 & $\begin{array}{l}\text { Range of normal controls } \\
23-24\end{array}$ \\
\hline
\end{tabular}

References are those from which normative data and percentile scores of single tests were derived. For the short recognition memory test for words (normative data collected from an Italian population are not available), the range of performance scores achieved by five age matched normal controls is reported. 
recency portion of the list (positions 11-15). In a group of 95 normal subjects investigated in our laboratory, the proportion of words recalled from the recency portion of the list was on average $32 \%$ (SD 7.2) of the overall number of words recalled. The patient also scored poorly on the 15 minute delayed recall of a short story, on the immediate and 15 minute delayed reproduction of Rey's complex figure and on a test assessing the ability to learn a spatial sequence on Corsi's test that exceeded his short term memory span.

The patient was also administered four subtests of the Camden memory battery ${ }^{27}$ exploring forced choice recognition of both visual and verbal stimuli. The first subtest (short recognition memory test for faces) evaluates recognition accuracy with 25 black and white photos of unfamiliar faces. Two other subtests (topographical recognition memory test and pictorial recognition memory test) evaluate recognition memory for 30 colour photos of topographical scenes. In the topographical test, the photos depict street scenes, parks, and buildings; in the pictorial test, buildings, animals, concrete objects, etc. The final subtest (short recognition memory test for words) explores forced choice recognition of 25 words. In this case, the original English words were replaced with high frequency Italian words.

As shown in table 2, the patient's scores were poor on the two tests exploring memory for topographical scenes and pictorial material (relative to normative data provided by Warrington $^{27}$ ) and on the word recognition test (relative to performance scores of five age matched normal subjects). However, the patient's score was within normal limits on the short recognition memory test for faces (25th percentile according to the normative data provided by Warrington ${ }^{27}$ ).

In summary, this patient had normal intelligence and obtained normal scores on tests of verbal and cognitive skills. For memory, his performance pattern closely resembled that found in patients with anterograde amnesic syndrome. He performed within normal limits on tests exploring short term memory functioning but was severely impaired on several tests evaluating long term episodic memory for verbal, visuoperceptual, and visuospatial information. A relevant exception to his pervasive episodic memory deficit was his normal score on a test evaluating the learning of unfamiliar faces. Normal performance on this test strikingly contrasts with his poor score on a test involving the learning of new topographical scenes. This is a dissociation opposite to the one described by Maguire and Cipolotti ${ }^{19}$ and Cipolotti et al, ${ }^{18}$ - that is, normal ability to learn unfamiliar faces but impaired learning of topographical material.

The following experimental investigation was conducted to confirm selective sparing of the patient's ability to learn new faces and to explore his memory for visual material learned before the onset of the amnesic syndrome (retrograde memory).

\section{Experimental investigation}

ASSOCIATIVE MEMORY FOR FACES, BUILDINGS, AND WORDS

We devised three tests to assess the ability to learn individual items and between item associations. The modality of administration was essentially identical but the nature of the memorandum varied: unknown faces, unknown buildings, and concrete words.

The experimental material for the face test consisted of 150 black and white photos of unknown male (120) and female (30) faces. For the building test, we selected 150 black and white photos of unknown buildings. The experimental material for the word test consisted of 150 concrete nouns; the frequency of occurrence ranged from 0 to $739 /$ million. For each test, the study phase consisted of the visual presentation of 30 pairs of items the subject was instructed to try to remember for a successive memory task. In the face test, the pair comprised a male and a female face. In the building test, non-categorically related items (for example, a church and a skyscraper) were selected. Finally, in the word test the words in each pair were not semantically related. Based on the results of a pilot study carried out on healthy young subjects to obtain comparable performance accuracy in normal controls on the three tests, we set the exposure time of individual pairs at 15 seconds. for the face and the building tests and at 3 seconds for the word test.

The testing phase immediately followed the study phase and also consisted of 30 trials, each articulated into two successive steps. The first step was a multiple choice recognition test for individual items. The patient was visually presented with four items, one previously seen in the study phase and three not previously seen. $\mathrm{He}$ was requested to point to the previously seen item. In the face test, all faces were males. In the building test, the four buildings in each trial were categorically related (for example, four skyscrapers, four country houses). Finally, in the word test, the alternatives were four concrete nouns all belonging to the same semantic category. Immediately after the individual item recognition test, the second step in each trial was the between item association recognition test. In this case, the individual item, which was the target of the previous recognition test, was presented together with the item it was associated with during the study phase and with three other items, all previously seen. In the face test, all four alternatives were female faces. In the building and word tests, the alternatives were categorically related. By requiring the subjects to select the associated item from the other previously studied items, we were confident that the patient's decision would not be based on a single item familiarity judgement (discriminating a previously seen item from three unseen ones) but would necessarily involve remembering the between item association.

Table 3 presents the performance scores of the patient and 15 age and literacy matched normal controls on the face, building, and word recognition tests. Manipulation of time exposures was effective in rendering not very 
Table 3 Patient's and 15 age matched normal controls'performances on the individual item and between item association memory tests for faces, buildings, and words

\begin{tabular}{|c|c|c|c|c|}
\hline \multirow[b]{2}{*}{ Test } & \multicolumn{3}{|l|}{ Patient scores } & \multirow{2}{*}{$\begin{array}{l}\text { Controls } \\
(n=15) \\
(\text { mean }(S D))\end{array}$} \\
\hline & Fanuary 1999 & February 1999 & October 1999 & \\
\hline \multicolumn{5}{|l|}{ Faces: } \\
\hline Individual item & 25 & 27 & 28 & $24.6(2.3)$ \\
\hline Between item association & 26 & 25 & 25 & $14.2(4.3)$ \\
\hline \multicolumn{5}{|l|}{ Buildings: } \\
\hline Individual item & 16 & & & $25.1(3.3)$ \\
\hline Between item association & 10 & & & $16.4(4.7)$ \\
\hline \multicolumn{5}{|l|}{ Words: } \\
\hline Individual item & 9 & & & $22.9(4.4)$ \\
\hline Between item association & 7 & & & $20.1(6.2)$ \\
\hline
\end{tabular}

dissimilar performance scores of normal subjects on the three tests. Moreover, in none of the tests was a ceiling effect seen in the normal controls' performance. On the face test, the patient's recognition of the individual items was in the range of the normal controls. In the between item association recognition test, his performance was remarkably good, almost 3 $\mathrm{SD}$ above the mean of the normal controls. By contrast, the patient's performance was poor in both the word and building tests. In particular, in both memory tests for individual items he scored about 3 SDs below the mean of the normal controls. In the between item association tests, his performance was chance (word test) or near chance (building test). However, as the normal controls scored considerably lower on the between item association tests than on the individual item recognition tests, the patient's performance fell 2 and 1.5 SD below the mean of the control group on the word and building tests, respectively. To verify the reliability of the high scores obtained by the patient on the face test, he was given the same test again twice, 1 and 9 months after the first administration. In both cases, the patient's scores were considerably above the mean of the normal controls on the individual item and between item association recognition tests (table 3 ).

RETROGRADE MEMORY FOR HUMAN FACES AND TOPOGRAPHICAL MATERIAL

Memory for faces and topographical material presumably learned before the onset of the amnesic syndrome was evaluated by means of a recognition memory test for famous faces, a recognition memory test for famous buildings, and a test requiring a verbal description of well known routes in Rome.

The recognition memory test for famous faces assesses the ability to identify a previously known face and to recall the relevant semantic data and proper name of the person identified. Each of the 20 items is composed of four black and white photographs of faces. In each item, one face is that of a celebrity (TV anchorman, folk singer, politician, etc) and the other three faces are of non-famous persons. Subjects are required to give three types of responses: (a) familiarity judgement (pointing to the face belonging to the famous person), (b) category (main occupation of the famous individual) and $(c)$ proper name.

In each of the 15 trials of the recognition memory test for famous buildings, one famous (for example, the Eiffel Tower, St Mary of the
Table 4 Performance scores of patient and five normal controls on the retrograde memory tests for faces, buildings, and routes

\begin{tabular}{lll}
\hline Test & Patient & $\begin{array}{l}\text { Controls } \\
\text { (range) }\end{array}$ \\
\hline Recognition of famous faces: & 17 & $17-20$ \\
$\quad$ Familiarity judgment & 17 & $17-20$ \\
$\quad$ Category & 17 & $16-20$ \\
$\quad$ Name & & \\
Recognition of famous buildings: & 15 & $13-15$ \\
$\quad$ Familiarity & 15 & $13-15$ \\
$\quad$ Town & 14 & $12-15$ \\
$\quad$ Name & 0.7 & $1.8-2.4$ \\
Route verbal description: & & \\
\hline
\end{tabular}

Angels Church in Florence) and three nonfamous buildings are presented simultaneously. Also in this case, the subjects are required to provide three responses: (a) familiarity judgement (pointing to the famous building), (b) verbally reporting the town in which the building is located, and (c) its name.

In the route verbal description test, the subjects are given the names of two well known places in Rome and are requested to verbally describe the shortest route linking the two places. The test consists of 10 trials. Performance was scored by three independent judges on a $0-4$ point scale based on accuracy of report. The overall score was computed by the mean of the scores in the 10 trials averaged across the three judges.

Table 4 reports the patient's results and those of the five age and literacy matched normal controls. The patient scored within normal limits on the recognition memory tests for faces and buildings. However, consistent with his reported difficulty in orienting himself in previously well known places in Rome, he scored well below the worst normal control on the route verbal description test.

\section{Discussion}

We reported on a patient who developed a severe impairment in the long term learning of new events and information after acute carbon monoxide poisoning. In the context of a memory deficit encompassing verbal information, abstract figures, concrete objects, topographical scenes, and spatial information, this patient was able to learn human faces at a normal (and, in some cases, at a higher) rate. He recognised recently encountered unfamiliar faces with the same accuracy as normal controls. He was also able to remember the association between two previously unfamiliar faces consistently better than a group of age and literacy matched normal controls. The dissociation between poor topographical memory and good memory for faces is very interesting. In fact, in the topographical domain the patient scored poorly not only on tests exploring memory for spatial arrays but also on tests investigating recognition memory for visual landmarks. This supports the case for a dissociation between poor and normal memory for different classes of visual objects.

An alternative explanation of the memory pattern exhibited by our patient in terms of the varying difficulty of the memory tasks administered is not supported by our results. Normal 
controls scored similarly on the three tests of individual item and between item association recognition memory. Also, no ceiling effect was seen in the normal subjects' performance that could have obscured a pathological performance by the patient. Indeed, patient's scores fell on the opposite side of the score distribution of normal controls on the face compared with the building and word recognition tests. In the first case, his score was above the normal subjects' mean; in the second, his performance was strikingly below the average performance of the age matched normals.

In the retrograde domain, the patient's memory deficit was far more limited. Although not formally investigated, the patient did not seem to have a relevant impairment in recalling autobiographical events that had occurred before the intoxication. Moreover, he easily recognised the faces of people who were familiar to him before the poisoning and scored normally on a task investigating the recognition of famous people. His only deficit in the visual memory of information acquired before the onset of the amnesic syndrome was difficulty in orienting himself in previously known routes. This deficit, which had already been noted in real life, was confirmed by a laboratory task requiring the verbal description of well known routes in Rome (the city in which he had always lived). However, as he had no difficulty in recognising the visual aspect of famous buildings (he performed at the ceiling in an ad hoc test), it is unlikely that his retrograde topographical disorientation was due to memory loss for the visual configuration of relevant landmarks. Rather, we are more prone to think that his orientation difficulty was spatial in nature, affecting his knowledge of the spatial relations among relevant landmarks and, possibly, a map-like representation of familiar environments.

This case draws a double neuropsychological dissociation with two recently reported cases of patients who were severely impaired in the new learning of unfamiliar faces but learned new topographical material (both the visual configuration of landmarks and routes) at a normal rate. ${ }^{18}{ }^{19}$ Our patient's performance pattern is also specular to that of another patient, recently reported by Tippett et $a l,{ }^{20}$ who had an isolated deficit in learning new faces. As previously noted, however, this patient was not examined for his ability to learn new topographical material. Therefore, we cannot be sure that his anterograde visuoperceptual memory impairment was really selective for the category of human faces. Overall, these data provide additional support for the hypothesis that the neural circuits underlying the memory for faces in the human brain are structurally and functionally independent from the circuits involved in the memorisation of other verbal or visual material and, in particular, of new topographical scenes. ${ }^{17}$ More interestingly, these results show that the selective sparing of visual memory for faces or topographical scenes may be limited to the anterograde domain.

The fact that memory for faces and memory for topographical material may be selectively and independently disrupted by cerebral damage supports the theoretical position that knowledge of the external world in the human brain is at least partially organised according to taxonomic categories. ${ }^{30}$ Regarding the neural base of this dissociation, the straightforward hypothesis that it reflects the fact that knowledge about different categories of objects is stored in topographically distinct areas of the human neocortex ${ }^{31}$ is generally contrasted with the most parsimonious hypothesis that different areas of the associative neocortex are specialised for the processing of different kinds of information and that these different kinds of information are differentially important for the identification of persons belonging to distinct taxonomic categories. ${ }^{32}$ Topographical scenes (such as buildings and landscapes) are large scale objects which are generally encoded in a locomotor space; knowledge about them is functionally relevant mainly if inserted in an allocentric map of environmental representation. ${ }^{4}$ Human faces, instead, are small scale objects which are more often processed in peripersonal space and their memory representation is generally encoded in an egocentric frame of spatial reference. So, if we assume that in the ventromesial surface of the temporal lobes distinct populations of neurons are differentially tuned to process large scale objects in an allocentric spatial frame or small scale objects in an egocentric frame of reference, then a pathological event selectively lesioning one of the two neuronal populations will result in a behavioural dissociation between impaired recognition of faces or topographical scenes. This line of reasoning has the obvious risk of circularity unless it is demonstrated that recognition of other objects which share some of the perceptual characteristics of faces or topographical scenes is also impaired in patients with a selective deficit in the recognition of faces or topographical material. This testing was not conducted in our patient, so on the basis of our data we are not able to discriminate whether the selective sparing in the anterograde memory for faces was really limited to this taxonomic category or whether it involved other classes of small scale objects to some extent.

The fact that our patient's memory impairment almost exclusively affected information acquired after the poisoning suggests that his cerebral damage did not affect the associative neocortex (considered to be the repository of consolidated memories) but rather the hippocampal circuitry. The critical role of the second in memory is generally held to be the transitory storage of recently acquired information ${ }^{33}$ and the successive long term consolidation of the same information in the associative neocortex. $^{34}$ The neuroradiological evidence of severe bilateral hippocampal atrophy in our patient and, at the same time, a lack of focal or diffuse damage to the associative neocortex is consistent with this view. On the other hand, the fact that the anterograde memory impairment affected all materials but spared the learning of human faces suggests that in the context of the hippocampal formation, the 
neural circuits underlying consolidation of different types of new information are reciprocally segregated and that, in the presently reported case, those involved in the storage of visuoperceptual information relative to human faces were selectively preserved.

1 Davidoff J, Matthews WB, Newcombe F. Observations on a case of prosopoagnosia. In: Ellis $\mathrm{HD}$, Jeeves MA Newcombe F, et al, eds. Aspects of face recognition. Dodrecht: Nijhoff, 1986:279-90.

2 Carlesimo GA, Caltagirone C. Components in the visual processing of known and unknown faces. I Clin Exp Neuropsychology 1995;17:691-705.

3 De Renzi E, Faglioni P, Grossi D, et al. Apperceptive and associative forms of prosopagnosia. Cortex 1991;27:21321 .

4 Incisa Della Rocchetta A, Cipolotti L, Warrington EK. Topographical disorientation: selective impairment of locomotor space? Cortex 1996;32:727-35.

5 Landis T, Cummings JL, Benson DF, et al. Loss of topographic familiarity. An environmental agnosia. Arch Neurol 1986;43:132-6.

6 McCarthy RA, Evans JJ, Hodges JR. Topographic amnesia: spatial memory disorder, perceptual dysfunction, or category specific semantic impairment? F Neurol Neurosurg Psychiatry 1996;60:318-25.

7 Whiteley AM, Warrington EK. Selective impairment of topographical memory: a single case study. $\mathcal{F}$ Neurol Neurosurg Psychiatry 1978;41:575-8.

8 Takahashi N, Kawamura M, Shiota J, et al. Pure topographic disorientation due to right retrosplenial lesion. Neurology 1997;49:464-9.

9 Tovée MJ, Cohen-Tovée EM. The neural substrate of face processing models: a review. Cogn Neuropsychol 1993;10: 505-28.

10 Habib M, Sirigu A. Pure topographical disorientation: a definition and anatomical basis. Cortex 1987;23:73-85.

11 de Haan EHF, Young AW, Newcombe F. A dissociation between the sense of familiarity and access to semantic information concerning familiar people. Eur 7 Cogn Psychol 1991;3:51-67.

12 Ross ED. Sensory-specific and fractional disorders of recent memory in man: I. Isolated loss of visual recent memory. Arch Neurol 1980;37:193-200.

13 Damasio AR, Damasio H, Van Hoesen GW. Prosopoagnosia: anatomic basis and behavioral mechanisms. Neurology 1982;32:331-41.

14 Levine DN, Warach J, Farah MJ. Two visual systems in mental imagery: dissociation of what and where in imagery disorders due to bilateral posterior cerebral lesions. Neurology 1985;35:1010-18.

15 Whiteley AM, Warrington EK. Prosopagnosia: a clinical, psychological and anatomical study of three patients. $\mathscr{f}$ Neurol Neurosurg Psychiatry 1977;40:395-403.
16 De Renzi E. Prosopagnosia in two patients with CT scan evidence of damage confined to the right hemisphere. Neuropsychologia 1986;24:385-9.

17 Aguirre GK, Zarahn E, D'Esposito M. An area within human ventral cortex sensitive to building stimuli: Evidence and implications. Neuron 1998;21:373-83.

18 Cipolotti L, Robinson G, Blair J, et al. Fractionation of visual memory: evidence from a case with multiple neurodevelopmental impairments. Neuropsychologia 1999; 37:455-65.

19 Maguire EA, Cipolotti L. Selective sparing of topographical memory. F Neurol Neurosurg Psychiatry 1998;65:903-9.

20 Tippett LJ, Miller LA, Farah MJ. Prosopamnesia: a selective impairment in face learning. Cogn Neuropsychol 2000;17: $241-55$.

21 Horowitz AL, Kaplan R, Sarpel G. Carbon monoxide toxicity: MR imaging in the brain. Radiology 1987;162: $787-8$.

22 Wechsler D. Wechsler adult intelligence scale. New York: Psychological Corporation, 1955.

23 Wechsler D. A standardized memory scale for clinical use. $\mathcal{F}$ Psychol 1945;19:87-95.

24 Raven JC. Progressive matrices (1947), Sets A, Ab, B: board and book forms. London: Lewis, 1949.

25 Carlesimo GA, Caltagirone C, Gainotti G, et al. The mental deterioration battery: normative data, diagnostic reliability and qualitative analyses of cognitive impairment. Eur Neurol 1996;36:378-84.

26 Nelson HE. A modified card sorting test sensitive to frontal lobe defects. Cortex 1976;12:313-24.

27 Warrington EK. The Camden memory tests manual. Hove, East Sussex: Psychology Press, 1996.

28 Orsini A, Grossi D, Capitani E, et al. Verbal and spatial immediate memory span: normative data from 1355 adults and 1112 children. Ital $\mathcal{F}$ Neurol Sci 1987;8:539-48.

29 Spinnler H, Tognoni G. Standardizzazione e taratura italiana di test neuropsicologici. Ital f Neurol Sci 1987; (suppl 8)

30 Hillis AE, Caramazza A. Category-specific naming and comprehension impairment: a double dissociation. Brain 1991;114:2081-94.

31 Warrington EK, Shallice T. Category-specific semantic impairments. Brain 1984;107:829-54.

32 Caramazza A, Shelton JR. Domain-specific knowledge systems in the brain: the animate-inanimate distinction. $\mathcal{F}$ Cogn Neurosci 1998;10:1-34.

33 Kapur N. Syndromes of retrograde amnesia: a conceptual and empirical synthesis. Psychol Bull 1999;125:800-25.

34 Squire LR. Memory and the hippocampus: a synthesis from findings with rats, monkeys, and humans. Psychol Rev 1992;99:195-231.

35 Zola-Morgan SM, Squire, LR. The primate hippocampal formation: evidence for a time-limited role in memory storage. Science 1990;250:288-90. 